\title{
Kurumsal Politik Davranış: İşletme, Devlet ve Piyasa İlişkileri Ekseninde Eleştirel Bir İnceleme
}

\author{
DOI: 10.26466/opus.606141
}

*

\section{Konuralp Sezgili*}

* Dr. Öğr.Üyesi Adana Alparslan Türkeş Bil.ve Teknoloji Üni. Siyasal Bilgiler Fak. Adana/Türkiye E-Posta: ksezgili@atu.edu.tr

ORCID: 0000-0001-6301-1805

\section{Öz}

Modern örgütlerin ortaya çıkışı ile özel ve kamusal aktörlerin rolleri arasında geçişlerin oluşması, bu aktörlerin yapı ve işlevlerinin incelenmesi konusunda karmaşık bir tablo yaratmaktadır. Kurumsal politik davranıs, kamusal ve özel çıkarların karşılıklı bağımlılığı içinde, işletmenin kamu politikası süreçlerini kendi lehine etkilemesi olarak tanımlanmaktadır. Stratejik yönetim düşüncesinin geleneksel olarak etkinliğ̈i odağa alan yaklaşımıyla uyumlu olarak kurumsal politik davranıs yazını da devlet etkinliğinin işletme üzerindeki etkilerine odaklanarak işletmeyi politik bir aktör olarak tanımlamış, politika çevresindeki süreç ve aktörleri de politik piyasa tasarımı çerçevesinde anlamaya çalışmıştır. Bununla birlikte, kamu kesimi ile özel kesim arasındaki sınırın yapay olduğu; bu yapay sınırı politik kararlar söz konusu olduğunda bireyler ve kurumlar tarafindan aşıldı̆̆ göz önüne alındığında, bu kurgunun gözden geçirilmesi gerektiği ortaya çıkmaktadır Bu çalışmada, klasik kurumsal politik davanış varsayımlarının tartışmalı sonuçları ışı̆̆ında devlet-işletme ilişkisi incelenmekte, bu alanda ortaya konan araştırma birikimi politika-strateji bağlamı içinde daraltılarak geleneksel strateji yaklaşımı değerlendirilmektedir. Yine, iktisadi etkinlik odağgnın sorun alanları ve bu alanların sorgulanmasına yönelik kuramsal katkılar da eleştirel bir perspektifle değerlendirilmekte, ileride yapılacak çalı̧̧malar için öneriler geliştirilmektedir.

Anahtar Kelimeler: Strateji, Kurumsal politik davranış, Kurumsal politik strateji, Kurumsal politik faaliyet 


\title{
Corporate Political Behavior: A Critical Review of Business, Government and Market Relations
}

\begin{abstract}
The emergence of modern organizations and the transitions between the roles of private and public actors created a complex panorama. Public and private interests are interdependent. While modern governments implement various types of interventions over the business, firms attempt to influence the institutional environment with the market and non-market activities. In line with the traditional approach of strategic management, corporate political behavior literature defines the business as a political actor, and display efforts to understand the processes in the policy environment resulting in performance. By reviewing the concept of corporate political behavior, this study aims to assess the contemporary construct and traditional strategy formulations of the corporate political behavior. Thus, this paper evaluates the government-business relation in light of controversial results of classical assumptions of strategic management through narrowing down the recent research literature within the context of policy and strategy. This paper further aims to provide future work recommendations.
\end{abstract}

Keywords: Strategy, Corporate political behavior, Corporate political strategy, Corporate political activity 


\section{Giriş}

Devletin özel kesimle ilgili politikalar üreterek yasa ve düzenlemeler hayata geçirmesi, bunların uygulanması ile ilgili tercih ve mekaniklerini oluşturması; geniş tarihsel arka planda politik-ekonomik örgütlenme ve devlet-işletme ilişkisinin kaçınılmazlığını gözler önüne sermektedir. Modern örgütlerin ortaya çıkışı ve özelde "işletme"nin üstlendiği baskın rol eşliğinde özel ve kamusal aktörler arasında geçişli bir zeminin varlığı, yirminci yüzyılın son çeyreğinde ilk dalgası yaşanan küreselleşmenin yarattığı uyum baskısı ile birleşerek (Doh, Lawton ve Rajwani, 2012) bu aktörlerin yapı ve işlevlerinin incelenmesi konusunda karmaşık bir tablo yaratmıştır. Öyle ki, kamu kesimi ile özel kesim arasındaki sınırın yapay olduğu; bu yapay sınırın politik kararlar söz konusu olduğunda bireyler ve kurumlar tarafından mütemadiyen aşıldığı ileri sürülmüştür (Kipping, 2003). Bu durum piyasa perspektifinin -ve geleneksel strateji düşüncesinin- odaklandığı piyasa ve piyasa-dışı alan ${ }^{1}$ (Baron, 1995) ikiliğinin gözden geçirilmesini zorunlu kılmaktadır. Bu inceleme, aynı zamanda kurumsal politik davranış ${ }^{2}$ yazınında yeni bakış açıları sağlayacak yaklaşımların ele alınması için de uygun bir zemin yaratmaktadır.

Devlet-işletme ilişkisi ve buna yönelik çalışmalar zengin bir akademik arka plana sahiptir33. Bu çalışmada, bu geniş arka plan, politika-strateji bağlamı içinde daraltılarak geleneksel strateji yaklaşımları (Hoskisson, Wan, Yiu ve Hitt, 1999) üzerinde sorun alanlarına ve kuramsal katkılara odaklanılmaktadır. Bu noktadan hareketle, ilk bölümde işletmenin politik kimliğini tartışılmakta; işletme açısından politik davranışın etkileşim çev-

\footnotetext{
${ }^{1}$ Kurumsal politik davranış yazınında sıklıkla yer alan "non-market" teriminin Türkçe karşlığı olarak "piyasa-dışı" teriminin kullanılması tercih edilmiştir. Piyasa-dışı alan işletmenin geleneksel pazar paydaşlarının dışında hükümet, siyasi partiler, politikacılar, idare, yargı, sendikalar, çıkar grupları gibi tarafların yer aldığı sosyal, politik ve yasal çevreyi ifade etmek üzere terimleşmiştir. Piyasa-dışı alanla ilgili ayrıntılı açıklamalar için bkz. Baron $(1995,1997,2001,2016)$. Yazında piyasa-dışı terimi yaygın olarak kullanılmakla birlikte, aynı anlama gelmek üzere kimi yazarlar piyasa-ötesi (beyond market) terimini tercih etmektedir (bkz. DeFigueiredo, Lennox, Oberholzer-Gee ve Vanden Berg., 2016).

${ }_{2}^{2}$ Işletmenin piyasa-dışı alanda sergilediği davranışlara yönelik terimleşen kurumsal politik davranış (corporate political behavior) kavramı; iki ilişkili kavram olaran kurumsal politik strateji (corporate political strategy) ve kurumsal politik faaliyet (corporate political activity) terimlerini kapsamaktadır (GorostidiMartinez ve Zhao, 2017).

${ }^{3}$ İsletme devlet ilişkisine yönelik geniş bir perspektif için bkz. Coen, Grant ve Wilson, 2010.
} 
resi incelenerek strateji sürecindeki politik öz ortaya konmaktadır. İşletmenin ekonomik olduğu kadar politik bir aktör olarak vasıflandırılması, stratejinin ekonomik ve örgütsel bileşenlerinin yanı sıra hem süreç hem de çıkı yönünden politik bileşenlerinin de değerlendirilmesi ihtiyacını beraberinde getirmektedir. Yani, piyasa-dişı stratejinin genel stratejinin önemli ve bütünleştirilmesi gereken bir bileşeni olduğu yönündeki kabul (Baron, 2001) "piyasa-dışı" kavramının ele alınmasını da gerektirmektedir. İkinci olarak, kurumsal politik davranışa ilişkin baskın geleneksel strateji yaklaşımlarının (Hadani ve Schuler, 2013) kuramsal çerçevesi incelenirken, mevcut "etkinlik" odağına ilişkin bulgular tartışmaya konu edilmekte, bu çerçevede son bölümde kuramsal olanaklar ve araştırma önerileri ele alınmaktadır. Bu çalışmanın birkaç temel noktada yazına katkı sağlayabileceği değerlendirilmektedir. Öncelikle, yerli yazında kurumsal politik davranışa ilişkin yeterli çalışma bulunmamaktadır. Türkiye' de işletme ve devlet ilişkisini farklı yönleriyle ele alan çok sayıda yetkin çalışma bulunmasına rağmen kurumsal politik davranış perspektifinin ilerleyen dönemde gelişmesi beklenebilir. İşletmenin politik davranışlarına ilişkin bu özgün çerçeve, Türkiye bağlamında üretilecek kurumsal politik davranış (faaliyet ve strateji) araştırmaları için katkı sağlayabilir.

\section{İşletme Politikasından Kurumsal Politik Davranışa İktisadi Etkinlik Düşüncesinin Arka Planı}

Kamu yararı ve özel çıkarlar birbirine bağımlıdır (Mahoney, McGahan ve Pitelis, 2009). Bu bağımlı ilişkide devlet, temel olarak, politika ve faaliyetleriyle işletme üzerinde sürekli etkilerde bulunmakta (Shapiro ve Taylor, 1990), işletme ise gerek faal olduğu piyasa sınırları içinde iş süreçlerini şekillendirme biçimi, gerekse piyasa-dışı alanda icra ettiği faaliyetler ile devlet ve hükümetler üzerinde etkili olmaktadır. Diğer bir deyişle devlet

\footnotetext{
${ }^{4}$ Genel olarak devlet ve işletme ilişkileri politik risk, özelleştirme, kamu özel ortaklıkları, işletme grupları ve girişimcilik gibi alanlarda çeşitli araştırmalara konu edilmektedir. Öte yandan kurumsal politik davranış ve piyasa-dışı strateji genç olmakla birlikte kendine özgü bir çalışma alanıdır.
} 
ve işletme stratejisi ilişkisi; bir yanda kamu politikalar1 ${ }^{5}$ ve buna bağlı siyasal, yasal ve idari işlemler, diğer yanda bu politikaları düzenli olarak izleyerek bunlara uyum sağlamak ve/veya politika yapımı ve uygulamasını biçimlendirmek durumunda olan örgütlerin varlığında gelişmekte ve bu haliyle girift bir görünüm arz etmektedir. İşletme ve devlet arasındaki güçlü ilişkiye yönelik geleneksel akademik ilgi (bkz. Coen vd., 2010) politika ve strateji bağlamına özgü çok sayıda araştırma kurgusunu beraberinde getirmiş; siyaset bilimi (Salomon ve Siegfried, 1977; Hansen ve Mitchell, 2000), sosyoloji (Mizruchi, 1992) ve ekonomi (Esty ve Caves, 1983) gibi çeşitli disiplinlerde işletmenin politik davranışına ilişkin açıklayıcı ancak bütünleşmeyen (Hadani, 2016) çerçevelerin oluşmasına zemin hazırlamıştır.

Stratejik yönetim yazını, işletme politikası olarak evrilmeye başladığı 1960'lı yıllardan itibaren geleneksel olarak işletme performansına ve bunu etkileyen çevreye odaklanmıştır. Dolayısıyla bu alanda kullanılan kuramsal yaklaşımlar firmanın içsel niteliklerine ağırlık vermiştir (Hoskisson vd., 1999). Aynı dönemde ABD'de hayata geçirilen yeni kamu politikaları (tüketici ve çevrenin korunması, çalışan sağlığı ve güvenliği vb.) aracıl1ğıyla devletin işletme davranışında sıkça değişiklikler talep etmeye başlaması ile devlet-işletme ilişkisinin çehresi değişmiştir (DeFigueiredo vd., 2016). Bu durum, işletmenin bir anlamda "kamu politikası değişikliklerine maruz kalması" ile sonuçlanacak pasif ya da reaktif stratejilerle kurumsal hedeflerini gerçekleştirmesinin sürdürülebilir olmadığı anlayışının gelişmesine sebep olmuştur (DeFigueiredo vd., 2016). Nitekim devletin uygulamada değişiklik talepleri işletmeler üzerinde farklı performans etkilerine sebep olmuş; bekleneceği üzere, strateji yazını bu farklılıkları ve buna yol açan öncülleri geleneksel etkinlik değerlendirmesiyle kaynaştırmıştır. Kaçınılmaz olarak, başarılı işletme performansına yol açan başarılı politik davranış bileşenleri, etkinlik ve performansın strateji yönetiminde işgal ettiği merkezi konuma benzer bir çekirdek oluşturmuştur. Dahası, 1970'lerde ulusal ve uluslararası piyasalarda sosyal ve ekonomik uyum

\footnotetext{
5 "Kamu politikası" kavramının temsil ettiği süreçler Funk ve Hirschman'a (2017, s.32) göre formel ve kodifiye kurallardır (yasalar, regülasyonlar ve mahkeme kararları). Yazarlara göre aynı şekilde politika yapıcılar; yasa koyucular, regülatörler (mevzuatın uygulanışında standartları belirleyenler) ve yargı üyeleri olarak belirtilmiştir. Yani, kamu politikasını üretenler yasama, yürütme ve yargı üyeleridir (Funk ve Hirschman, 2017).
} 
baskısının artması, çok uluslu işletmelerin boy göstermesi ${ }^{6}$ ve gelişmiş piyasalarda regülasyonların yarattığ ${ }_{1}$ ortam (Mitnick, 1993) işletme-devlet ilişkilerinin karşılıklı bağımlılığını daha da güçlendirmiş; bu ilişkinin "tarihte hiçbir zaman şimdiki kadar önemli olmadığı" (Vogel, 1996) yorumunu beraberinde getirmiştir. Bir bütün olarak değerlendirildiğinde tüm bu değişimler, işletmenin -geleneksel strateji yönetimi kapsamında- etkili bir plan ve eylem tasarımı için kamu politikaları süreçlerini içeren bir piyasa-dışı alan tanımı yapmak zorunda kalmasıyla sonuçlanmıştır ${ }^{7}$ İki yeni kavrayış; yani (a) işletmenin politik bir öze sahip olması ve (b) politik bir aktör olarak piyasanın yanı sıra piyasa-dışı alanda faaliyetler sergilemesi; ekonomik ve örgütsel strateji ve faaliyetlerin yanı sıra politik strateji ve faaliyetlere, yani kurumsal politik davranışa ilişkin yaklaşımların gelişmesini sağlayan düşünsel zemini yaratmıştır. İzleyen başlıkta bu zeminin yapısı tartışılmakta, bunu politik faaliyetlerin değerinin ve yarattı̆̆ sonuçların tartışılması izlemektedir.

\section{Piyasa-Dışı Alanda Politik Bir Aktör Olarak İşletme}

Kurumsal politik davranış yazınının gelişmeye başladığı ilk çalışmalardan bu yana, işletme bakımından politik süreçler içinde yer alma istekliliği -veya kimi araştırmacılara göre zorunluluğu- konusunda genel bir meşruiyet oluştuğu fikri büyük ölçüde kabul görmüştür (bkz. Stigler, 1971). Söz gelimi, Salamon ve Siegfried (1977) Amerikan demokrasisini anlamanın yolunun, idarenin efendileri olarak tanımlanan işletme ile politik güç arasındaki ilişkiyi anlamaktan geçtiğini ileri sürmektedir8.

\footnotetext{
${ }^{6} 1970$ 'lerde binlerle ifade edilen olan çok uluslu işletme sayısı en güncel veri yılı olan 2008 yılına gelindiğinde 82 bin işletmeye çıkmıştır. Ayrıca -tüm ülkeleri kapsamamakla birlikte- 2018 yılına gelindiğinde dünyanın çeşitli noktalarında çok uluslu işletmelere bağlı 230 bin şirket bulunduğu kaydedilmektedir (OECD, 2018).

${ }^{7}$ Geleneksel olarak performans farklılıklarına ve başarılı performansı destekleyen pratiklere yer verdiği bilinen stratejik yönetim yazını 1970'lerden itibaren endüstriyel örgüt kuramına referansla endüstri yapısı ve rekabetçi pozisyona yönelerek firmanın çevresiyle etkileşimini öne çıkarmaya başlamıştır (Hoskisson vd., 1999). İlginç biçimde, kurumsal politik davranış yazınının tarihsel arka planını ele alan çalışmalarda, stratejik yönetimdeki bu odak değişiminin benzer şekilde kurumsal politik davranış yazınında da gerçekleşmiş olduğunda dikkat çekilmemektedir.

8 1913-1921 yılları arasında görev yapan 28'inci ABD Başkanı Woodrow Wilson, sermaye sahipleri ve üreticileri "Amerikan idaresinin efendileri" (The masters of the government of United States) olarak tanımlamıştır (Wilson, 1913).
} 
1980'li yıllarda kurumsal politik davranışa ilişkin araştırmalar, önceki bölümde ana hatları ile belirtildiği üzere kamu politikalarını strateji yönetimi içinde tanımlamış, bu çerçevede işletmenin genel etkinliğinin artırılmasına odaklanarak kurumsal politik davranışı (politik strateji ve faaliyetleri) incelemeye yoğunlaşmıştır (Gorostidi-Martinez ve Zhao, 2017). Bu yönelim önemli bir dönüm noktasını da oluşturmaktadır, zira kurumsal politik davranış; işletmenin amaçlarına ulaşması için çeşitli araçlarla politika kararlarını ve uygulamalarını etkilemesi şeklinde de anlaşılmıştır9 Diğer bir deyişle, performans sonuçlarını değiştirecek kamu politikası yapım ve uygulama alanı, çeşitli stratejik manevralarla meşru biçimde müdahale edilebilecek bir alan kimliği kazanmıştır. Dolayısıyla politik davranışın işletme stratejisinin ve işletme değerinin önemli bir bileşeni haline gelmesi kaçınılmaz olmuştur (örn. Hillman ve Hitt, 1999; Fisman, 2001, Oliver ve Holzinger, 2008).

Sonuç olarak, kamu politikalarının oluşturulması ve uygulanması ile bu sürece katılanların ilgisine bağlı olarak- modern piyasaların işletme bakımından farklı türde fırsatlar sunması yeni bir pencere yaratmıştır (Keim ve Hillman, 2008). Artık işletme kamu politikaları değişikliklerine maruz kalan pasif bir özne değil, bu değişikliklerin yaratabileceği fırsatlardan faydalanabilecek "proaktif" bir aktör olarak yeniden konumlanmıştır. Dolayısıyla firsatlardan yararlanmak isteyen işletmenin "farklı katılma düzeylerinde politika oluşturma ve uygulama süreçlerinde yer alma istekliliği sergilemesi -diğer bir deyişle politik davranışlar sergilemesi- olağan olarak nitelendirilmiştir. Örneğin Keim ve Hillman'a (2008, s.48) göre “işletmenin içinde bulunduğu politik çevreyi iyi anlaması; yöneticilerin fırsat ve tehditleri daha iyi değerlendirmesine olanak sağlayabileceği gibi, işletmenin hâlihazırdaki ve gelecekteki çevreyi şekillendirmesine yardımcı olacak stratejilerin formüle edilmesine de imkân verebilir". Yani,

\footnotetext{
${ }^{9}$ Bu yaklaşım değişimi güç perspektifiyle anlaşılabilir (örn. Salorio, Boddewyn ve Dahan, 2005) politik davranışı etkileme gücü ile açıklamaktadır. Bu perspektif, amaca ulaşmak için dirençleri aşılması gereken diğer sosyal aktörlerle kurulan iliş̧i içinde gücün kazanımını, geliştirilmesini ve güvenceye alınmasııı işaret etmektedir (Boddewyn ve Brewer, 1994). Kurumsal politik davranış, bu çerçevede, "piyasa-dışı çevre içinde elverişli pozisyonu almak için işletmenin genel ekonomik performansını etkileye(bile)n diğer piyasa dışı aktörlerin etki ve/veya direncinden kaynaklanan belirsizlikleri ve kaynak bağımlııklarını yönetmesi yoluyla yaptığı eylemler" olarak tarif edilmektedir. Bu doğrultuda işletmenin ekonomik olduğu kadar politik öze sahip bir örgüt olarak ele alınması gerektiği ve politik davranışın evrensel ve sürekli olduğu belirtilmektedir (Salorio vd., 2005, s.30).
} 
politika değişikliklerinden etkin olarak faydalanmanın yanında, aynı zamanda bu kararları biçimlendirmek yoluyla çıar sağlanabileceği fikri kurumsal politik davranışın sınırlarına yerleşmiştir. Bunu ortaya koyan bir örnekte Hillman ve Hitt (1999) bu durumu; ulusal ve uluslararası politika yapım alanı ticaretin kurallarını belirlerken, işletmenin rekabet pozisyonunu etkileyen politika yapım ve uygulama alanına -piyasa dışı alanadaha fazla nüfuz etmeye çalışması olarak ifade etmektedir. Bu halde, bir tercihin ötesine geçmiş olduğu kanıksanan kurumsal politik davranışın işletmeye sağladığı fayda ve dolayısıyla işletme performansı bakımından değerlendirilmesinin (Hillman, Keim ve Schuler, 2004) doğal bir sonuç olarak ortaya çıkmış olduğu anlaşılabilir.

Ele alınması gereken bir diğer kavram piyasa-dışı alandır. Politik katılım bağlamında işletme doğasının hazır bulunuşluğuna ilişkin inanış ve piyasa-dışı stratejinin genel stratejinin önemli ve bütünleşmesi gereken bir bileşeni olduğu yönündeki kabul (Baron, 2001), piyasa-dışı kavramının incelenmesini önemli kılmaktadır. İşletme açısından müdahale ve etki alanı çerçevesinde tanımlanan piyasa, ekonomik faaliyetleri çevreleyen ekonomik piyasalar olduğu gibi, işletmeyle etkileşim içindeki sosyal, politik ve yasal çevreden oluşan piyasa-dışı çevreyi de içermektedir (Baron, 1995). Yukarıda ortaya çıkış gerekçeleri ifade edilen piyasa-dışı çevrede sergilenen faaliyetler kurumsal politik stratejinin esasını oluşturmuştur. Politik davranışın işletme değerinin önemli bir bileşeni olarak benimsenmesi; politik strateji izlemenin gerekleri ve etkili bir politik strateji izlemenin işletme lehine yaratacağı faydaların ayrıntılı biçimde incelenerek sonuçların ortaya konmasını gerektirmiştir ${ }^{10}$. Bununla uyumlu olarak, piyasa-dışı alanda sergilenen kurumsal politik davranış bir örgütün kamu gücünü özel çıkarları için kullanma çabası olarak tarif edilmiş (Mitnick, 1993); bu çabanın araçları olarak politik nüfuz (Getz, 1993; Schuler, 1996), ABD'de büyük bir sektör olan lobicilik (Martin 1995; Mathur and Singh,2011; Antia vd., 2013) ve politik eylem komiteleri oluşturma (Masters ve Keim, 1985; Hansen ve Mitchell, 2000) ile diğer çeşitli politik taktikler (Schuler, 1996; Lyon ve Maxwell, 2004) ele alınmıştır. Kısaca strateji yazını, Şekil 1'de ana hatları verildiği üzere, kurumsal politik davranışı ortaya çıkaran öncüller

\footnotetext{
10 Piyasa-dışı alana ilişkin strateji ve taktikleri ele alan ve strateji yazınını büyük ölçüde etkileyen kavramsal çalışmalar için bkz. Yoffie ve Bergenstein 1985; Boddewyn ve Brewer, 1994; Shaffer, 1995; Hillman ve Hitt, 1999.
} 
(Hacim, hükümete bağımlılık düzeyi, örgütsel bolluk, iş çeşitlendirme, yabancı sermaye, yaş, yapıların formalleşme düzeyi, yönetsel etki gibi işletme değişkenleri; firma sayısı ve yoğunlaşma gibi endüstriyel değişkenler; belirginlik ve rekabet gibi sorun değişkenleri; kurumsal farklılıklar), politik faaliyet türleri (proaktif/reaktif, yaklaşım, katılma düzeyi ve strateji tipleri) ile çıktılar üzerine odaklanmıştır (Hillman vd., 2004). Ne var ki ilerleyen başlıklarda tartışıldığı üzere piyasa-dışı alanda politik stratejinin değeri ve ortaya çıkardığı sonuçlar halen tartışmalıdır (Hadani, 2016).

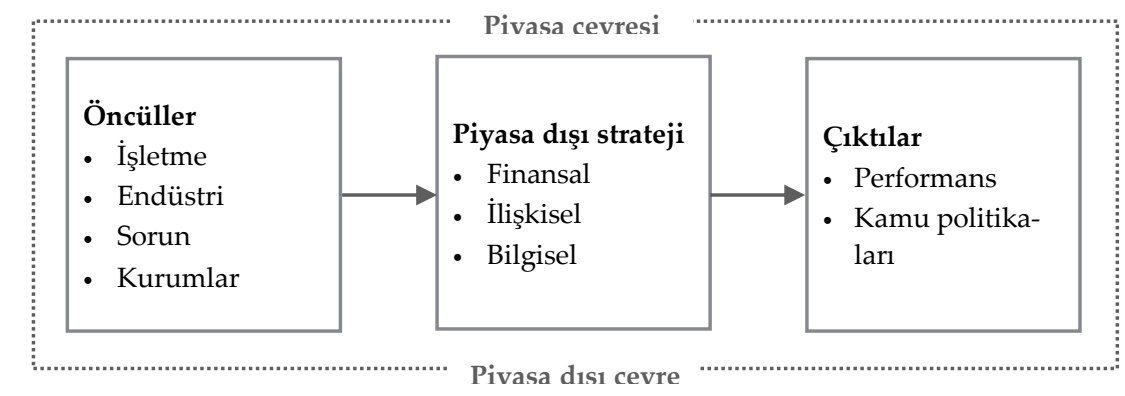

Şekil 1. Piyasa odakl yaklaşımda kurumsal politik strateji süreci Kaynak: Hillman ve Hitt (1999) ve Hillman, Keim ve Schuler'den (2004) uyarlanmıştır.

\section{Strateji Yaklaşımlarında Geleneksel Zemin ve Sorun Alanları}

İşletmenin politik öze sahip bir örgüt olarak piyasa ve piyasa-dışı alanda faaliyetler sergilemesi, gerek genel yönetim gerekse spesifik olarak stratejik yönetim araştırmaları kapsamında iki kuramsal yaklaşımın (politik pazar ve kaynak bağımlılığı) hakim biçimde kullanılması ile gelişmiştir (Hadani ve Schuler, 2013). Bunların ilki olan politik pazar yeri yaklaşımı (Bonardi vd., 2005), stratejik yönetimin etkinlik kaygısını paylaşır bir içerikte, işletme-devlet etkileşimini bir tür politik piyasa değişimi olarak analiz etmekte ve politik piyasaların ne zaman cazip olduğunu açıklamaya çalışan bir çerçeve sunmaktadır. Bu yaklaşım politika alanını bir piyasa olarak tanımlayarak kamu politikası süreçlerini arz-talep etkileşimi biçiminde açıklamaya çalışmaktadır. Bu etkileşimde işletme, kamu politikasını etkileme amacıyla bilgi, finansman ve politik destek gibi değerli kaynaklar sunmaktadır (Boddewyn ve Brewer, 1994; Bonardi, Hillman ve Keim, 
2005). Piyasa işlemlerini (transaction) odağa alan bu yaklaşım -stratejik yönetimdeki genel eğilimle uyumlu olarak- politik avantajlar için işletmelerin birbiriyle rekabet içinde olduğunu da vurgulamıştır (Bonardi vd., 2005). Bu bakış açısıyla politik davranışın gerek politik piyasa değişimini kolaylaştırmak gerekse politik tehlikeleri azaltmak yoluyla işletme değerine katkıda bulunabileceği öngörülmektedir (Sun, Mellahi ve Wright, 2012). Sun ve arkadaşlarına (2012) göre buradaki önemli nokta, politik piyasaların işleyiş̧inin ekonomik piyasalara göre çok daha yüksek işlem maliyeti doğurması ve bu piyasalarda apaçık bir fiyat mekanizması bulunmamasıdır. Bu noktada, işletme ve politika yapıcı arasında sözleşme belirsizliği yüksek olmakta ve siyasi oportünizm kaynaklı riskler bulunmaktadır. Ayrıca, politik piyasa söz konusu ise geleneksel işlem maliyetlerinde bulunan içselleştirme (internalization) imkânı bulunmadığı belirtilmekte, sözleşme tehlikelerini bertaraf etmek için işletmelerin özel yönetişim yapıları oluşturmaları gerektiği öngörülmektedir (Sun vd, 2012).

İkinci olarak kaynak bağımlılı̆̆ı kuramı (Pfeffer ve Salancik, 2003) piyasa yerine sosyal değişimi merkeze alarak, işletmenin karşılıklı bağımlılık içinde sürekli sosyal değişim ilişkileri içinde olması nedeniyle çok sayıda kaynak sağlayıcıya bağımlı olacağını belirtmektedir. Bu çerçevede araştırmalar, örgüt ve diğer çevresel aktörler arasındaki güç dengesizlikleri, işletmenin dış çevredeki bağımlılıklarını yönetmesi için kurulan kişisel ve örgütsel bağlantılar ile politik paydaşlarla benimsenen işbirliği türlerine odaklanmaktadır. (Sun vd, 2012). Bu perspektifi benimseyen araştırmalar, özellikle yönetim kurullarındaki politika kökenli yöneticilerin varlığı ile örgütün meşruiyeti arasındaki ilişkiye, güçlü politik aktörlerle kurulan ağların sağladığı fırsatlara ve kamu politikasına ilişkin bilgi ve kaynaklara erişim konularına odaklanmaktadır (Sun vd., 2012; örn. Hillman, 2005).

Strateji geleneği içerisinde diğer bir kuramsal yaklaşım, kaynak tabanlı yaklaşımın (Barney, 1991) kurumsal politik davranışa uyarlanmasıyla ortaya çıkmıştır. İşletmeyi heterojen kaynaklar demeti olarak yorumlayan bu yaklaşım uyarınca Hillman ve Hitt (1999), politik kaynak çeşitliliğine sahip işletmelerin bireysel stratejiler üzerinde yoğunlaşacağını, buna mukabil kaynak bakımdan görece fakir olan işletmelerin kolektif eylemleri kullanacağını öngörmektedir. Yazarlar ayrıca, firma düzeyinde var olan kaynakların yanı sıra kurumsal farklılıkların (Granovetter, 1985) politik 
faaliyet seçimini etkileyeceğini öngörmektedir. Nihayet, çeşitli ampirik araştırmalarda olası faydaların maliyetlerden üstün bulunması, politik çevre ile ilişkilerin -özellikle performans bakımından- değer yarattığı sonucuna ulaşılmasını beraberinde getirmiştir (Sun vd., 2012, s.71). Özetle, bağımlılık ve belirsizlikle değer üretecek biçimde başa çıkmanın yöntemleri, kurumsal politik strateji düşüncesinin çekirdeğini oluşturmuştur (Hillman ve Hitt, 1999; Hillman, 2005).

Uygulamada gerek politik davranış süreçleri, gerekse politik davranışın değer yaratması varsayımı üzerinde geniş bir tartışma bulunmaktadır. Lux, Crook ve Woehr (2011) tarafından yapılan meta-analizde; politik davranışın işletme performansı ile sıkı bağlara sahip olduğu, arzu edilen kamu politikalarını güvence altına almak için kullanılabileceği; bununla birlikte içerdiği risk bakımından diğer yatırımlarla karşılaştırıldığında politik faaliyetlerle elde edilebilecek getirinin beklendiği düzeyde olmayabileceği ya da çok daha büyük olabileceği belirtilmektedir. Ayrıca bu düşünce ile uyumlu olarak devlet-işletme ilişkilerini ve sonuçlarını ölçecek yeni temalar geliştirilmektedir. Finansal stratejiler açısından bakıldı̆̆ında, örneğin Faccio $(2006,2010)$ "politik bağlantılılık"11 kavramı aracilı̆̆ıyla politik bağlantıların değer yarattığı varsayımını çeşitli bulgularla desteklemektedir. Öte yandan bazı araştırmalarda ise öncekilerin aksine politik yatırımların piyasa performansı ile ilişkisinin zayıf ve bağlama göre değişebilir (Hadani, Bonardi ve Dahan, 2017), kimi zaman kamusal sonuçları itibariyle negatif ilişkili (Hadani ve Schuler, 2013) olduğu tespit edilmiştir $^{12}$. Bu çelişki, etkilerinin varlığı konusunda tartışma bulunmayan ancak sonuçlarının değer yaratabilirliği tartışılan kurumsal politik strateji kav-

\footnotetext{
${ }^{11}$ Çoğunlukla politik ekonomi ve finans araştırmalarında rastlanılan politik bağlantılıık (political relatedness) kavramı işletme yöneticileri ve politikacılar arasında kurulan çeşitli ilişkiler bağlamında ölçülmektedir; örneğin politikaya giren büyük hissedarlar ve işletme yönetimine katılan politikacılar (Faccio, 2006), büyük hissedarlar ve politikacılar arasındaki dostluk ilişkileri, yabancı politikacılarla geliştirilen ilişkiler (Faccio, 2010). Bu bağların özellikle banka kredileri ve devlet ihalelerinin dağıtımı çerçevesinde ifade ettiği önem birçok ülke örneğinde araştırmalara konu edilmiştir.

${ }^{12}$ Bu araştırmada eski kamu görevlilerini yönetim kurullarına yerleştiren işletmelerin bu durumda olmayan işletmelerden daha düşük performans sergilediği tespit edilmiştir. Yine de, regüle edilmiş endüstrilerde politik davranış ve performans arasında pozitif ilişkiler bulgulanmıştır.
} 
ramına ihtiyatla yaklaşılması gerektiğini ortaya koymaktadır. Yine, çoğunlukla ilişkisel stratejiler ${ }^{13}$ bağlamında, mevcut yazının gelişmiş ülkelere özgü kurgulardan oluştuğu ve farklı ülke bağlamlarında kısıtlı bir içgörü sağladığı belirtilmektedir (Hillman ve Hitt, 1999; Rajwani ve Liedong, 2015; Gorostidi-Martinez ve Zhao, 2017). Örneğin, ABD'de çevresel bağımlılık ve belirsizlikle başa çıkmanın bir yolu olarak işletmelerin yönetim kurullarında eski politikacılara yer verilmesinin performans üzerinde kayda değer sonuçlar yarattığı ifade edilmiştir (Hillman, 2005). Aksini ortaya koyan çalışmalarda da (örn. Hadani ve Schuler, 2013) genellikle regülasyon düzeyi gibi istisnai koşullar dışında politik davranışın performans üzerinde tartışmalı etkiler yarattığı ileri sürülmektedir. Bu çerçevede araştırmaların yeni temalar, aktörler ve bağlamlar üzerinde çeşitlenmesi şaşırtıcı değildir. Gelişmekte olan ülkeler üzerinde yapılan yeni çalışmalarda, ilişkisel strateji türlerinin bu ülkelerde -etkileri bakımındandaha önemli sonuçlar yaratabileceği ortaya konmaktadır. Çoğunlukla kurumsal boşluk tezinden hareket eden bu çalışmalar sosyal sermaye, kayırmacılık ve yolsuzluk gibi temalar üzerinde yoğunlaşmaktadır. Örneğin Haveman, Jia, Shi ve Wang (2017), Çin örneğinde kaynak bağımlılığı ve politik gömülülük fikrini birlikte ele aldıkları çalışmada, otoriter rejimlerde pazarların gelişmesi ile işletmelerin bürokrasinin çalışma biçimini öğrenerek kamu politikaları süreçlerinde fırsatları anlayabileceğini, bu şekilde belirsizliği azaltabileceklerini ortaya koymaktadır.

Strateji ve performansa ilişkin çelişkili bulgulara ek olarak, politik pazaryeri yaklaşımı, kamu politikalarının oluşum süreçlerini piyasa dinamikleriyle açıklamaya çalışması bağlamında eleştirilmektedir. Bu yaklaşım kapsamında, özellikle işletme-devlet etkileşiminde kamu otoritesinin tek güç olarak incelenme eğilimi, bu otoritelerin işletmenin sunacağı kaynaklara (bilgi, finansman ve politik destek) koşulsuz itibar edebileceği düşüncesi, etkileşimin cereyan ettiği kurumların ve politik karar alma sürecinin ideolojik yapısının ihmal edilmesi, temel eleştiri noktaları arasında

\footnotetext{
${ }^{13}$ Hillman ve Hitt (1999) sınıflamasına göre ilişkisel stratejiler işbirliğine dönük, uzun vadeli ve sorunu daha geniş bir çerçevede kapsayıcı ve öngörücü strateji biçiminde betimlenirken işlemsel (transactional) stratejiler kısa vadeli, geçici ve sorun odaklıdır.
} 
yer almaktadır (Greiner, 2018) ${ }^{14}$. Bu noktada, Mahoney ve arkadaşlarının (2009) belirttiği gibi, özel ya da kamusal örgütlere ilişkin sorgulamaların genel olarak bir diğerinin rolünün yeterince vurgulanmamasıyla sonuçlandığının ${ }^{15}$ altı çizilmelidir. Sonuç olarak, temel kuramsal hareket noktalarının zaman zaman çelişkili bulgularla birleşmesi, kurumsal politik davranış yazınında kavramsal ve kurgusal zenginleştirme çağrılarının da tekrarlanmasını beraberinde getirmiştir. Diğer bir deyişle, etkili bir strateji için piyasa ve piyasa dışı stratejilerin nasıl bütünleştirilebileceği hala bir soru olarak varlığını korumaktadır.

\section{Tartışma ve Sonuç}

Görece uzun süredir bilinen ancak nadiren dillendirilen bir çalışma sahası olan kurumsal politik davranış (Schuler, Rehbein ve Cramer, 2002), ekonomi ve işletme disiplinlerinin baskın görünümünün yanı sıra siyaset bilimi ve sosyoloji disiplinlerinden önemli katkılar almıştır (Gorostidi-Martinez ve Zhao, 2017). Son yıllarda strateji alanında konuya gösterilen ilginin önemli ölçüde arttığı; davranış, bağlam ve performans ilişkilerinin disiplinler arası kurgularla zenginleştiğii görülmektedir. Strateji, klasik olarak belirsizliğe karşı belirli prosedürler geliştirme süreci olarak tanımlandığında (Bracker, 1980); kurumsal politik davranış kavramının neden stratejik yönetim düşüncesinin merkezinde konumlandığı ve belirsizliğin azaltılarak etkinliğin artırılmasının neden bu kavramın merkezinde yer aldığı anlaşılabilir. Bununla birlikte, bütünleşik yaklaşımların geliştirilmemesi, politik süreçlerle ilişkili birçok değişkenin varlığ ve kurumsal politik strateji alanında yaşanan niceliksel yoğunlaşma, Doh ve arkadaşlarının (2012) belirttiği üzere, piyasa dışı strateji alanını önemli ölçüde kimlik sorunuyla yüz yüze bırakmaktadır.

\footnotetext{
${ }^{14}$ Bu eleştirilerin ana fikri; politika yapıcının işletme çevresindeki bir aktör olarak ele alınmasına mukabil, politika yapıcının da -işletme gibi- kendi çevresi bağlamında ele alınması gerekliliğinin ihmal edilmesidir. Bu yaklaşımı ayrıntılı bir biçimde inceleyen bir çalışma için bkz. Greiner (2018).

${ }^{15}$ Mahoney ve arkadaşlarına (2009) göre bu durumun sonucu olarak, yönetim araştırmaları kapsamında öncelikle işletmenin kamu yararı çerçevesinde regülasyon ve benzeri kamu politikası araçlarıly nasıl kısıtlandığı açıklanmaya çalışılmıştır. Diğer yandan kamu yönetimine odaklanan çalışmalar, bu tip kurum ve kuruluşların işletmelerin örgütsel sistemleri, yapıları ve uygulamalarından sağlayabileceği faydalara (örn. kamu yönetimi süreçlerinin "stratejik yönetimi") odaklanmıştır. Sonuç olarak, çeşitli türlerdeki kuruluşların karmaşık karakterlerine eş yoğunluklu vurgunun nadiren yapıldığı belirtilmektedir.
} 
Stratejide işletmenin politik bir aktör olarak "keşfi" ve işletme-devlet ilişkilerinin bununla bağlantılı olarak ele alınma biçimleri, iktisadi etkinlik odağı etrafında gelişmiştir. Chandler iktisadının büyüyen firmayı odağa alması; geleneksel strateji yaklaşımlarında da bununla uyumlu olarak "devletin etkinliğinin işletmenin performansına etkilerinin" baskın biçimde ele alınmış olması, tartışmalı bir kavram olarak "değer yaratan" politik strateji geliştirme çabaların da beraberinde getirmiştir. Diğer bir deyişle, piyasa-dışı alanda var olan belirsizliklerin yönetilmesi için politika kararlarını ve uygulamalarını etkilemek "etkinlik sorununu" beraberinde getirmekte; "piyasa dışı alanla bütünleşik doğru bir strateji oluşturma, uygulama ve ortaya çıkan sonuçları ölçme", piyasa odaklı yaklaşımın temel sorunu haline gelmektedir. Oysa hâlihazırda, devlet müdahalesi ve piyasaların gelişmesi üzerinde sonu gelmeyen tartışmalar; işletmenin piyasa ve piyasa-dışı veya ekonomik ve politik piyasa tasarımını muğlaklaştırmakta; devlet-işletme ikilisi arasında tanımlanamayan alanlar, bağlamsal farklılıklar ve politika oluşturma sürecinde yer alan karmaşık aktörler, bu tartışma etrafindaki temel eksenler haline gelmektedir.

Kamusal açıdan bakıldığında, Kipping'e (2003) göre, tüm bağlamlarda varlığ1 tartışma götürmeyecek "kamu etkisi" kavramı; ilk tartışmalara ev sahipliği yapan Anglo-Amerikan kapitalizminde -yanıltıcı biçimde- yok sayılma eğiliminde olmuştur. Bununla uyumlu olarak kurumsal politik davranış yazınında da devletin etkisinin genel olarak yeterli düzeyde incelenmediği ileri sürülebilir. Kamu etkisi, ülkeler hatta bölgeler arasında oldukça farklılaşabilen pratiklere sahne olmakla birlikte, kurumsal politik davranış yazınında genel eğilim gelişmiş ve gelişmekte olan/geçiş ülkeleri bağlamında karşılaştırmaların önerilmesi şeklinde kendini göstermektedir. Tarihsel ve karşılaştırmalı perspektiften bakıldığında, işletme performansının piyasa ve diğer kurumların performansı bağlamında gömülü olması (Mahoney vd., 2009); birçok sosyal ve kurumsal yapının geleneksel çerçeveyi daha anlaşılabilir kılmasına olanak sağlayabilir. Örneğin kamu politikası oluşturma süreçlerinde yer alan politik partilerin sayısı ve gücü, yasama organının gücü, bürokrasinin gücü, politik meşruiyet, politik kültür gibi politik kurumlar kurumsal politik davranışın anlaşılmasında önemli çerçeveler sağlayabilir. Temsili demokrasi ve kapitalizmin anahtar konumundaki aktörleri olan politik partiler ve işletmeler arasındaki bağlar, diğer aktör bakımından siyaset biliminde (Wilson ve Grant, 2010) ve 
stratejik yönetim disiplininde yeterince ilgi görmeyen bir alandır. İstisnai çalışmalardan birinde Zhu ve Chung (2014), iktidarın tek bir politik partide toplandığ 1 durumlarda, hem iktidar hem muhalefet partisiyle politik bağlara sahip olmanın yeni pazarlara girişte engeller yarattığ1 sonucuna ulaşmıştır. Bir diğerinde Haveman ve arkadaşları (2017), otoriter rejimlerde pazarların gelişmesi süreciyle birlikte işletmelerin bürokrasinin çalışma biçimini öğrenerek kamu politikaları süreçlerindeki fırsatları tanılayabileceğini, bu şekilde belirsizliği azaltabileceklerini ortaya koymaktadır. Farklı olarak, örneğin bir ülkedeki politik partilerin disiplin gücünün yüksek olması, parlamento üyelerinin parti denetçilerinin talimatları yönünde hareket etmesini beraberinde getirecek (Roskin, 1995); bu durumda kurumsal politik stratejilerin, işletmeyi etkileyen/etkileyebilecek yasa ve düzenlemeleri hayata geçiren parlamenterlerden ziyade, partiyi yöneten çekirdek kadroya odaklanması söz konusu olabilecektir. Benzer şekilde, bir ülkede bürokrasinin güçlü olması, politik faaliyetlerinin yasama organı yerine bürokrasiye yönelmesinde etkili olabilecektir. Kurumsal politik davranış bağlamında kamu politikalarının uygulama sürecinde yargının rolü ve işletme ile yargı temsilcileri arasındaki ilişkiler de incelenmesi tercih edilmemiş alanlardan biri olarak kalmıştır.

Piyasa perspektifinde bakıldığında da ele alınan eleştirilerle uyumlu olarak yeni arayışlar gözlenmektedir. Kurumsal politik davranış araştırmalarının genel olarak piyasa-dışı alana yönelmesi, işletmenin piyasa faaliyetleriyle politika süreçlerini etkileyip etkileyemeyebileceğinin göz ardı edilmesine sebep olmuştur. Yeni çalışmalardan birinde Funk ve Hirschman'a (2017) göre işletme, uygulaması belirsiz politikaları yorumlar ve uygularken, politika yapıcının bu politikanın uygulamasına ilişkin kavrayışını değiştirmek suretiyle politika işlevini dönüştürebilir. Ayrıca işletme yeni ürün ve hizmetler geliştirmek ve yeni faaliyetlerde bulunmak yoluyla da politikaların etkilerini şekillendirebilir. Diğer bir deyişle, işletmenin piyasa faaliyetleri de piyasa dışı alandaki politikaları etkileme gücüne sahiptir.

Son olarak, kamu politikası oluşturma süreçlerinde işletme-devlet etkileşiminin sınırında yer alan kurumların incelenmesinin de önemli fırsatlar sağlayabileceği değerlendirilmektedir. Örneğin Hillman ve Hitt (1999) firma kaynaklarının çokluğu -ve dolayısıyla hacimsel büyüklük- ile poli- 
tik katılımın artacağını varsaymaktadır. Cook ve Fox (2000) ise aksine, küçük firmaların daha aktif politik katılım sergilediğini bulgulamakta; Hillman ve arkadaşları (2004) bu durumu kolektif eylem (Olson, 2008) ile açılamaktadır. Bu durumda küçük firmaların kolektif eylemi hayata geçirebileceği ara yüz niteliğindeki yapıların (iş insanlarının sivil toplum girişimleri, kamusal görevleri, eğitimleri vb.) bağlamsal gücü ve bölgesel niteliği (örn. yeni kurumsal yaklaşım ve ulusal iş sistemlerin yaklaşımları) farklı politik davranışların anlaşılmasında önemli bir çerçeve sağlayabilir. Nihayet, Türkiye'de benzer çabalar büyük işletmeler ve işletme gruplarına odaklanan araştırmalar bağlamında yoğun olarak sergilendiğinden, işletme gruplarında kurumsal politik davranışın anlaşılması bu alandaki araştırmacılar için yeni fursatlar sağlayabilir. 


\title{
EXTENDED ABSTRACT
}

\section{Corporate Political Behavior: A Critical Review of Business, Government and Market Relations}

\author{
Konuralp Sezgili \\ Adana Alparslan Türkeş Science\& Tecnology University
}

The emergence of modern organizations and the transitions between the roles of private and public actors created a complex panorama. By reviewing the concept of corporate political behavior (CPB), the aim of this study is to assess the contemporary construct and traditional strategy formulations of the CPB. This paper further aims to provide future work recommendations.

Public and private interests are interdependent. Besides, the increasing density of social and economic integration in national and international markets, the emergence of multinational enterprises and regulations in developed markets further strengthened the interdependence of businessgovernment relations. While modern governments implement various types of interventions over corporates, firms attempt to influence their institutional environments with both market and non-market activities. Historically, in line with Chandler's economic focus on the growth of the firm, researchers in the $\mathrm{CPB}$ area traditionally offered insights into how convenient political strategies and tactics secure favorable situations and therefore increase the overall effectiveness of the firm. That is, traditional strategic management approaches have prioritized the effects of government activities on firm performance. This orientation also marked an important milestone, as CPB was understood to influence policy decisions and practices through a variety of tools to achieve the objectives of the business, which has led to efforts to develop value-oriented political strategies. At that point, influencing policy decisions to manage the uncertainties existing in the non-market area yielded the general efficiency problem: developing, implementing and measuring the suitable strategy integrated within the non-market area. In other words, the field of public policymaking and implementation process has become a field that can be legitimately 
intervened by various strategic manoeuvres. Consequently, political behavior remained an important component of business strategy and business value. Accordingly, firms are required to define a non-market area and build a strategic framework for influencing public policy processes for an effective overall strategy and action design. The two insights; namely, (a) the firm has a political essence, and (b) the firm -as a political actor- operates in the market as well as non-market area, have led to the debate of the value of the political activities and their benefits. Research has shown that political behavior is closely linked to business performance and is used to secure desired public policies; however, in terms of the risk, the returns from political activities may not be at the expected level or maybe much larger compared to other -mostly financial- investments. On the other hand, some researchers have found that the relationship between political investments and market performance is weak and may vary depending on the context and even negatively related to public results. Controversial findings reveal the need for a cautious approach to the concept of corporate political strategy.

From a historical and comparative perspective, considering social and institutional structures may form the traditional framework more coherent. For example, political institutions such as the number and power of political parties, the legislative power, the power of bureaucracy, political legitimacy, and political culture can provide important frameworks for understanding corporate political behavior. The complex links between political parties and business as key actors of representative democracy and capitalism are the area that does not receive enough attention in both political science and strategic management disciplines. From a market perspective, recent research shows that in the context of uncertain policies, firms can modify the functions of these policies by transforming the policymaker's understanding of the implementation of this policy. Firms can also shape the impact of policies by developing new products and services and engaging in new activities. In other words, the market activities of the firms have the power to influence the policies in the non-market area. Consequently, examining the institutions at the edge of business-state interplay may provide valuable opportunities for future studies. Some research suggests that political participation is positively related to the size of resources and structure of the firm. Some research, in contrast, found that 
small firms exhibit more active political participation. The interfaces (nongovernmental initiatives, public service, educational background of the owner, etc) of collective action may provide an important framework for understanding different political behaviors.

Finally, the current literature provides limited insight to make inferences in diverse, especially in developing and less-developed country contexts. At the same time, the ongoing debates on the state intervention and the development of markets make the firm's market/non-market design ambiguous. Unidentified areas between state and business, contextual differences, and complex actors involved in policymaking become key issues around this discussion. Therefore, further research can be expected to diversify on new themes, actors and contexts.

\section{Kaynakça / References}

Barney, J. (1991). Firm resources and sustained competitive advantage. Journal of management, 17(1), 99-120.

Baron, D. P. (1995). Integrated strategy: Market and nonmarket components. California management review, 37(2), 47-65.

Baron, D. P. (1997). Integrated strategy, trade policy, and global competition. California management review, 39(2), 145-169.

Baron, D. P. (2001). Private politics, corporate social responsibility, and integrated strategy. Journal of economics \& management strategy, 10(1), 745.

Baron, D. P. (2016). Strategy beyond markets: A step back and a look forward. İçinde: Strategy beyond markets (ss. 1-54). Emerald group publishing limited.

Baysinger, B. D. ve Woodman, R. W. (1982). Dimensions of the public affairs/government relations function in major American corporations. Strategic management journal, 3(1), 27-41.

Boddewyn, J. J. ve Brewer, T. L. (1994). International-business political behavior: New theoretical directions. Academy of management review, 19(1), 119-143. 
Bonardi, J. P., Hillman, A. J. ve Keim, G. D. (2005). The attractiveness of political markets: Implications for firm strategy. Academy of Management Review, 30(2), 397-413.

Bracker, J. (1980). The historical development of the strategic management concept. Academy of management review, 5(2), 219-224.

Coen, D., Grant, W. ve Wilson, G. (Eds.). (2010). The Oxford handbook of business and government. Oxford University Press.

Cook, R. G. ve Fox, D. R. (2000). Resources, frequency, and methods: An analysis of small and medium-sized firms' public policy activities. Business \& Society, 39(1), 94-113.

De Figueiredo, J. M., Lenox, M., Oberholzer-Gee, F. ve Vanden Bergh, R. G. (2016). İçinde: Strategy beyond markets. (ss. iii). Emerald Group publishing limited.

Doh, J. P., Lawton, T. C. ve Rajwani, T. (2012). Advancing nonmarket strategy research: Institutional perspectives in a changing world. Academy of management perspectives, 26(3), 22-39.

Esty, D. C. ve Caves, R. E. (1983). Market structure and political influence: New data on political expenditures, activity, and success. Economic Inquiry, 21(1), 24-38.

Faccio, M. (2006). Politically connected firms. American economic review, 96(1), 369-386.

--- (2010). Differences between politically connected and nonconnected firms: A cross-country analysis. Financial management, 39(3), 905-928.

Fisman, R. (2001). Estimating the value of political connections. American economic review, 91(4), 1095-1102.

Funk, R. J. ve Hirschman, D. (2017). Beyond nonmarket strategy: Market actions as corporate political activity. Academy of management review, $42(1), 32-52$.

Gorostidi-Martinez, H. ve Zhao, X. (2017). Corporate political strategies: a contemporary literature review. Journal of Advances in Management Research, 14(3), 375-404.

Granovetter, M. (1985). Economic action and social structure: The problem of embeddedness. American journal of sociology, 91(3), 481-510.

Greiner, M. (2018). The political landscape: A new approach to understanding corporate political activity. Wayne state university dissertations. 2015. 
Hadani, M. (2016). Corporate political activity and public policy outcomes: New realities and increasing challenges. The SAGE handbook of international corporate and public affairs, 259.

Hadani, M., Bonardi, J. P. ve Dahan, N. M. (2017). Corporate political activity, public policy uncertainty, and firm outcomes: A meta-analysis. Strategic organization, 15(3), 338-366.

Hadani, M. ve Schuler, D. A. (2013). In search of El Dorado: The elusive financial returns on corporate political investments. Strategic management journal, 34(2), 165-181.

Hansen, W. L., ve Mitchell, N. J. (2000). Disaggregating and explaining corporate political activity: Domestic and foreign corporations in national politics. American political science review, 94(4), 891-903.

Haveman, H. A., Jia, N., Shi, J. veWang, Y. (2017). The dynamics of political embeddedness in China. Administrative Science Quarterly, 62(1), 67-104.

Hillman, A. J. (2005). Politicians on the board of directors: Do connections affect the bottom line?. Journal of management, 31(3), 464-481.

Hillman, A. J., ve Hitt, M. A. (1999). Corporate political strategy formulation: A model of approach, participation, and strategy decisions. Academy of management review, 24(4), 825-842.

Hillman, A. J., Keim, G. D. ve Schuler, D. (2004). Corporate political activity: A review and research agenda. Journal of Management, 30(6), 837857.

Hoskisson, R. E., Wan, W. P., Yiu, D. ve Hitt, M. A. (1999). Theory and research in strategic management: Swings of a pendulum. Journal of management, 25(3), 417-456.

Lux, S., Crook, T. R. ve Woehr, D. J. (2011). Mixing business with politics: A meta-analysis of the antecedents and outcomes of corporate political activity. Journal of management, 37(1), 223-247.

Keim, G. D. ve Hillman, A. J. (2008). Political environments and business strategy: Implications for managers. Business horizons, 51(1), 47-53.

Kipping, M., (2003). Business-government relations: Beyond performance Issues, Amatori, F. ve Jones, G. İçinde, Business history around the world (ss. 372-393). Cambridge: Cambridge university press. 
Lyon T. P. ve Maxwell, J. W. (2004). Astroturf: Interest group lobbying and corporate strategy. Journal of economics $\mathcal{E}$ management strategy, 13(4), 561-597.

Mahoney, J. T., McGahan, A. M. ve Pitelis, C. N. (2009). Perspective-The interdependence of private and public interests. Organization science, 20(6), 1034-1052.

Masters, M. F. ve Keim, G. D. (1985). Determinants of PAC participation among large corporations. The journal of politics, 47(4), 1158-1173.

Mitnick, B. M. (Ed.). (1993). Corporate political agency: The construction of competition in public affairs (Vol. 163). Sage Publications.

Mizruchi, M. S. (1992). The structure of corporate political action: Interfirm relations and their consequences. Harvard university press.

OECD (2018). Multinational enterprises in the global economy: Heavily debated but hardly measured. Policy Notes.

Oliver, C. ve Holzinger, I. (2008). The effectiveness of strategic political management: A dynamic capabilities framework. Academy of Management Review, 33(2), 496-520.

Olson, M. (2008). Collective action. The New Palgrave Dictionary of Economics: Volume 1-8, 876-880.

Pfeffer, J. ve Salancik, G. R. (2003). The external control of organizations: A resource dependence perspective. Stanford university press.

Rajwani, T. ve Liedong, T. A. (2015). Political activity and firm performance within nonmarket research: A review and international comparative assessment. Journal of World Business, 50(2), 273-283.

Roskin, M. G. (1995). Countries and concepts: an introduction to comparative politics. Prentice Hall.

Salamon, L. M. ve Siegfried, J. J. (1977). Economic power and political influence: The impact of industry structure on public policy. American political science review, 71(3), 1026-1043.

Salorio, E. M., Boddewyn, J. ve Dahan, N. (2005). Integrating business political behavior with economic and organizational strategies. International studies of management $\mathcal{E}$ organization, 35(2), 28-55.

Schuler, D. A., Rehbein, K. ve Cramer, R. D. (2002). Pursuing strategic advantage through political means: A multivariate approach. Academy of Management Journal, 45(4), 659-672. 
Shaffer, B. (1995). Firm-level responses to government regulation: Theoretical and research approaches. Journal of management, 21(3), 495-514.

Shapiro, H. ve L. Taylor. (1990). The state and industrial strategy. World development 18(6), 861-878.

Stigler, G. J. (1971). The theory of economic regulation. The Bell journal of economics and management science, 3-21.

Sun, P., Mellahi, K. ve Wright, M. (2012). The contingent value of corporate political ties. Academy of management perspectives, 26(3), 68-82.

Vogel, D. J. (1996). The study of business and politics. California Management Review, 38(3), 146-165.

Wilson, W. (1913). The new freedom: A call for the emancipation of the generous energies of a people. Doubleday, Page \& Company.

Wilson, G. ve Grant, W. (2010). Business and political parties. İçinde: The Oxford handbook of business and government (ss.191-207). Oxford: Oxford university press.

Yoffie, D. B.ve Bergenstein, S. (1985). Creating political advantage: The rise of the corporate political entrepreneur. California management review, 28(1), 124-139.

Zhu, H. ve Chung, C. N. (2014). Portfolios of political ties and business group strategy in emerging economies: Evidence from Taiwan. Administrative Science Quarterly, 59(4), 599-638.

\section{Kaynakça Bilgisi / Citation Information}

Sezgili, K. (2019). Kurumsal politik davranış: İşletme, devlet ve piyasa ilişkileri ekseninde eleştirel bir inceleme. OPUS-Uluslararası Toplum Araştırmaları Merkezi, 13(19), xxxx-xxxx. DOI: 10.26466/opus.606141. 